\title{
Editorial
}

\section{A clínica aberta e o analista grupo: suas transferências e o comum}

Tales Ab'Sáber*1

\section{Contexto}

\begin{abstract}
A partir do ano 2014 ocorreu no Brasil um movimento amplo de tomada dos espaços públicos por trabalhos livres, coletivos e sociais de psicanalistas. Esse movimento de socialização da psicanálise e de discussão clínica e teórica das suas bases mercantilizadas antecedeu a viravolta radical à direita da vida política do país, que criminalizou de modo parcial a esquerda institucional, o partido trabalhista de Lula, e levou ao poder um governo híbrido de neoliberalismo e neofascismo, bem brasileiro. De todo modo que se veja, um movimento radicalmente contrário a toda vida social que realize trabalho coletivo, comum e de acesso livre universal. As clínicas psicanalíticas públicas, no entanto, prosseguiram seus trabalhos com toda vitalidade. Sua força vinha de suas
\end{abstract}

${ }^{* 1}$ Universidade Federal de São Paulo - Unifesp (São Paulo, SP, Brasil). 
raízes teóricas e de sua verdade social. A Clínica Aberta de Psicanálise, na Casa do Povo em São Paulo, foi uma das precursoras do movimento, que hoje se tornou nacional, em confronto espiritual à conversão da vida ao egoísmo e ao abandono social mais radical, muito próprio da nova direita do Brasil.

A psicanálise foi profundamente marcada pela fantasia estruturadora, real-ideológica, da realidade psicossocial do indivíduo, sua existência e seus problemas. A disciplina de Freud se constituiu originalmente no campo dos efeitos da vida do indivíduo moderno, como ideia de psicologia da figura heroica do indivíduo pessoal - e do médico herói-científico, como tantos outros heróis, na cultura do mercado simbólico dos indivíduos — um ente psicológico existente e integrado sob as intensidades plurais das múltiplas esferas da existência na modernidade. Como uma concepção ideológica que também o compõe, a multiplicidade da vida própria das práticas modernas foi enfeixada e remetida à ideia figurada da responsabilidade monádica de cada um, um superego cultural ideológico, de efeitos narcísicos. Assim se configurou o campo da aventura do sujeito individual, o "homem livre" no mercado aberto dos destinos possíveis da expansão constante do capital sobre as vidas, com sua 502 jornada social e íntima e sua formação através do mundo inteiramente moderno.

São conhecidas algumas figuras ideológicas subjetivas em meio ao processo histórico de tal psicologia, e ideologia prática, que se generalizava: o puritano protestante e sua solidão ética pessoal radical diante de Deus e da Bíblia, o herói burguês fáustico que sozinho cria o mundo industrial e desenha a nova sociedade, a imagem dos Robinsons Crusoés sociais isolados, tão criticada por Marx, como senhor pragmático de ciência e de técnica, onipotente, ou ainda a figura do artista romântico genial, ou seu filósofo que, sempre sós, construíam ou desconstruíam todo o sentido de seu mundo.

Podemos verificar claramente essa figura titânica da subjetivação moderna em toda literatura romanesca do século XIX, bem como podemos, com a psicanálise, e o limite histórico das ilusões do mundo da expansão infinita do progresso - com sua ordem de destruição geral que se apresentou inteira no século XX - verificar sua crise, um esgarçamento simbólico e emocional para si mesmo inclusive. Essa real dimensão falha e incompleta do indivíduo moderno, de sua razão histórica e sua metafísica do iluminismo, que perde valor para si própria no auge de seu próprio processo de configuração histórica, foi muito representada na literatura avançada da modernidade, de Flaubert e Dostoievsky, Machado de Assis e Henry James, a Kafka ou a Becket. De fato, a literatura de ponta do romance do indivíduo moderno 


\section{EDITORIAL}

configurou e antecipou em tudo, e em detalhes, o mundo da teoria e da necessidade de trabalho psicanalítico sobre um eu que não se resolvia mais de nenhum modo em si próprio nem por si mesmo. Porque os artistas e os poetas sabiam diretamente aquilo que o homem de ciência precisava acessar por meio de seu trabalho duro, dizia Freud. Aquele indivíduo racional e autônomo moderno, uma entidade teórico-ideológica pressuposta com efeitos subjetivantes, foi, com seu próprio desenvolvimento, questionado em suas raízes e estruturas psicopolíticas, pela literatura do seu tempo, pela ciência do enigma do inconsciente da psicanálise, bem como por parte significativa da filosofia contemporânea. Na melhor das hipóteses o indivíduo se tornou uma figura conceitual e política, parcial e alienada de modo próprio, em relação às forças múltiplas e muitas outras que passamos a compreender que o compõe.

No trabalho coletivo que apresentamos aqui, sob a crise contemporânea da reprodução da vida na ordem da modernidade tardia, do capitalismo turbinado e total do mundo de hoje - degradante da vida sobre a terra, questionador permanente do espaço da organização política pública e produtor do espetáculo da validade única da imagem e da mercadoria no mundo humano, seu único sujeito - o dispositivo e os efeitos de existência do grupo, articulado ao modo psicanalítico, nos parecem entidades e potências para a vida tão verdadeiras e produtivas quanto um dia foi o tradicional indivíduo moderno, herói de páginas de romance de seu tempo, e do setting social original, de caráter burguês, mas pós-burguês... do psicanalista. Esse deslocamento que propomos, na imagem e na composição do sujeito que articula uma psicanálise no mundo, implica deslocamentos políticos e de fantasias inconscientes de toda ordem, que reanimam nosso entendimento do trabalho clínico, em conjunto com a sua sempre presente política no mundo, oculta ou revelada, e suas virtualidades e potências em um mundo crítico.

Um chiste pode nos dar uma notícia condensada dessas modulações de vida e criação próprias aos grupos: a psicanalista Marília Velano certa vez comentou sobre os grupos de trabalho de psicanalistas, que os analistas, coletivamente, formam escolas..., mas nunca conseguem formar... uma banda de rock! O que essas limitações do trabalho coletivo dos analistas são e o que implicam? A Clínica Aberta de Psicanálise e Grupo Analista, formulada por mim e por um grupo de colegas em São Paulo, no Brasil, é uma resposta concreta a essa questão.

Apresentamos aqui algumas falas e posições emocionais pontuais expressas por pacientes - ou usuários, ou cidadãos... - durante o trabalho analítico realizado na Clínica Aberta de Psicanálise na Casa do Povo, um 
centro cultural de acesso universal, em um bairro central de São Paulo que conjuga classe média e pobreza brasileiras. Estas falas revelam, para um começo de apresentação, a complexa e sensivelmente rica modalidade de transferência, ou transferências, em muitos níveis - verticais, grupais, coletivos, pessoais, institucionais ou com o próprio dispositivo, setting coletivo - que o trabalho do analista ou terapeuta grupal, o analista-grupo, como viemos a chamá-lo, realizado naquela clínica de amplo acesso, produz e reconhece. Os nomes aos quais os pacientes se referem são os nomes de alguns dos analistas que se revezam em seus atendimentos, mas entendendo cada paciente como paciente do grupo de analistas e não de um analista indivíduo específico, desde a instauração do modelo de ampliação e deslocamento da psicanálise de grupos, próprio deste setting:

“... a Marília me falou uma coisa da outra vez que fiquei pensando..., que eu era como um avião que voava sempre na mesma faixa, que nunca saia do mesmo modo e espaço, embora pudesse..."

"que mulher a Annie..., foi importante para mim a conversa com ela..."

"encontrei o Tales da última vez, e ele estava com uma camisa de 504 futebol... hoje quando estava vindo para cá me lembrei disso... eu tinha colocado uma camisa de futebol..., se isso não for transferência, então eu não sei o que é..."

"no começo eu fiquei pensando... será que dá certo esse modo de falar cada vez com uma pessoa? Achava que eu teria que falar tudo de novo a cada vez que eu falasse com um analista diferente... hoje, que já vim aqui tantas vezes, vejo que não é assim... eu falo o que quero e estou pensando em cada vez, e não preciso repetir a história nada... é porque vocês fazem um trabalho conjunto né, que todos vocês ficam sabendo da gente, não é isso?"

"fico pensando, vocês são diferentes..., cada um é um, a Miranda é a Miranda, o Ricardo é o Ricardo, o Fabrício é o Fabrício, cada um tem um jeito... cada um fala de um jeito... mas vocês são muito parecidos também..., são parecidos..., por que será?"

"fico pensando, achava que seria difícil falar com pessoas diferentes em cada sessão. Mas não é nada disso. Cada vez que venho para cá penso, com quem será que vou falar hoje? Eu não sei. E isso me parece bom. Hoje penso o contrário do que achava no começo. Cada um me diz uma coisa, me vê de um jeito, tem um jeito de falar diferente. É bom isso, essa relação com vários analistas. Fico pensando que, se eu falasse sempre com a mesma pessoa, 


\section{EDITORIAL}

sempre com o Ricardo, ou com você, talvez eu estivesse me repetindo, talvez eu tivesse parado nas mesmas coisas, só com aquela pessoa... deste modo eu não me repito... e isso é bom..."

“... só estou contando novamente esse sonho pra você para que os analistas tenham uma continuidade do trabalho..."

"estou vindo aqui porque me disseram que aqui é um lugar de recomeço de vida..."

Em cada uma dessas frases recolhidas da vida da clínica a psicanálise se atualiza e revela a sua produtividade diferencial, revista pelo deslocamento teórico/real do setting original realizada no trabalho. Esses são apenas alguns dos efeitos transferenciais do setting de clínica pública e de movimento de psicanálise social, na vida na cidade, da Clínica Aberta de Psicanálise. Um trabalho em que psicanalistas se revezam semanalmente em um plantão clínico, consideram os pacientes pacientes do grupo analítico dos analistas, o chamado analista-grupo, e não pacientes individuais de analistas individuais e desenvolvem um trabalho coletivo de elaboração e "sonhação" analítica sobre os pacientes, e o grupo de pacientes, o paciente-grupo. Estamos na esfera da polifonia do sonho, da articulação de múltiplas criações do inconsciente individual com o trabalho do inconsciente de um grupo (Kaës, 2002/2006). Todas as etapas do trabalho se dão segundo e através do método freudiano fundamental: associação livre de pacientes articulada à escuta flutuante, com suspensão de desejo e de memória por parte dos analistas. Bem como o trabalho elaborativo associativo do grupo analítico dos psicanalistas sobre, ou sob, os pacientes, em espaço-tempo próprio para isso.

Essas estruturas de comprometimento grupal e social estão inteiramente atravessadas em todos os seus momentos pelo método psicanalítico primeiro, o fio que unifica e faz trabalhar todos os estágios da ideia de clínica social realizada aqui, articulando-a, assim, ao modelo fundamental do inconsciente freudiano e testando-o com esta outra forma. Por isso trata-se de psicanálise, e não de outra modalidade de recebimento clínico. Na multiplicação dos indivíduos, para a potência do grupo, e para potência do setting cultural e social que se produz, é a própria psicanálise em seu princípio fundamental que se vê multiplicada. Trata-se de uma clínica que, como veremos, vem da tradição do campo psicanalítico, nela se inscreve e lê seus resultados por seus critérios e parâmetros.

O primeiro ponto a ser observado de uma nova estrutura humana de encontro e experiência, um setting psicanalítico, funcionando sobre o regime do método freudiano e seu modelo de inconsciente de fundo, é que ele pode 
nos dar reais e concretas novas notícias sobre o inconsciente e suas potências de sentido (Anzieu, 2000/2004). Vejamos um exemplo histórico conhecido. O analista e pediatra Donald Winnicott, por exemplo, só chegou a reconhecer e pensar a nova lógica psicanalítica dos objetos e fenômenos transicionais após 25 anos de trabalho em um setting renovado da sua psicanálise presente na clínica pública em um hospital pediátrico inglês (Winnicott, 1936/1988; 1941/1988), que chegava a alcançar bebês e suas mães. Sua ação psicanalítica pública não era coincidente com o setting analítico pessoal e individual no qual ele próprio se formara. E esse deslocamento não apenas ampliou o poder de presença social da psicanálise no mundo, como levou a produção de problemas clínicos e teóricos que ainda não haviam sido percebidos ou pensados. O setting, a natureza sensorial da relação de cuidado, sua forma escolhida de espaço, tempo e presença, seu lugar na vida simbólica e cultural da cidade e a configuração humana e política do analista, ou dos analistas, que ele implica e propõe, sempre foi a verdadeira fonte da vida teórica da psicanálise. E também seu destino. De fato, a psicanálise emana de sua experiência viva, a sua coisa simbólica que é um acontecimento, para poder chegar a ser pensada. E, num segundo tempo, como teoria, a psicanálise também retorna aos seus settings. Na origem, antes de todo dado teórico propriamente psicanalítico, em primeiro lugar a psicanálise foi uma experiência humana clínica de setting, o espaço clínico original ético e vazio, inventado e estabelecido por Josef Breuer, antes de Freud, de onde surgiram as experiências fundamentais sob o estatuto da observação e da presença do analista, que permitiram ao gênio de Freud o desenvolvimento radical, teórico e clínico de seu saber (Breuer \& Freud, 1895/2017), em um segundo tempo.

A Clínica Aberta de Psicanálise é um setting psicanalítico. Um setting que, na sua própria forma de se apresentar, sua forma política de organizar e propor práticas na vida e na cultura, seu caráter de dispositivo biopolitico, como dizia Foucault, articula elementos sociais e teóricos da disciplina psicanalítica de um modo novo. Esse modo de pensar e organizar a psicanálise no mundo só é possível hoje, após 120 anos da experiência psicanalítica histórica continuada e acumulada, porque conta integralmente com a presença da história em sua constituição. Ele é uma articulação contemporânea das possibilidades teóricas desta história, suas múltiplas observações e construções de muitas ordens da experiência psicanalítica. Esse setting organiza, torna orgânicos, os seguintes elementos heterogêneos, unificados agora por um desejo social comum: espaço público, sujeito grupal dos analistas em trabalho, criação mútua do local de trabalho com os pacientes, plantão clínico 


\section{EDITORIAL}

de acesso livre e universal, ausência de sobrecarga burocrática ou controle social pela mediação do dinheiro, escuta atenta aos potenciais de comunicação da sessão única, revezamento dos analistas no atendimento continuado aos pacientes que desejem prosseguir o trabalho e projeto terapêutico desenhado pelo paciente, seja apenas uma ou várias sessões, com entendimento não pedagógico nem adaptativo do que é uma análise. Esta configuração responde precisamente ao potencial de deslocamento múltiplo, a plurivocidade do inconsciente freudiano, nas próprias palavras de Freud sobre a formação dos sonhos, e ao estatuto do inconsciente do funcionamento grupal, como observado por Rene Käes e seu grupo de trabalho em Lyon.

A existência histórica dos momentos potenciais de sentido intensos na sessão única, já pesquisada com crianças desde o trabalho pediátrico psicanalítico de Donald Winnicott nos anos de 1930 a 1970 (Winnicot, 1971/1984), a disciplina da atenção emocional ao aqui-e-agora, entendimento central à tradição kleiniana, que se desdobra e complementa o método psicanalítico da escuta flutuante e da associação livre com o trabalho de suspensão de desejo e de memória - numa des-referência excessiva a passado e a futuro por parte do analista - (Bion, 1967/1990) e o grupo de elaboração inconsciente dos analistas sobre os pacientes, bem como sobre o grupo dos pacientes (Käes, 2006), são os elementos da história da psicanálise que foram unidos e sintetizados na forma de produção de experiência com o inconsciente freudiano que chamamos Clínica Aberta e o Grupo Analista. Assim, a clínica, como estrutura de intervenção contemporânea, é, de fato, uma leitura da história da psicanálise.

Além disso, sob outra perspectiva, também está em jogo a radicalização do vínculo político-social das práticas analíticas e sua produção de sistemas simbólicos socialmente orientados, de modo a conceber a reprodução da realidade simbólica do mercado liberal como uma contingência e não como uma estrutura real da psicanálise. A clínica é um ato político, psicanalítico, de interesse radicalmente comum, onde novas práticas de existência e desalienação da ideia e do lugar do trabalho, para pacientes e para analistas, devem advir. Psicanálise grupal, coletiva e social, na raiz da possibilidade do acesso universal como desejo, e, portanto, sem a regulação socialmente desigual, politicamente controlada, do dinheiro (Brown, 2016). Novas práticas de circulação e ocupação da vida, na cidade, fazem parte do novo trabalho de clínica. Acentua-se o valor do trabalho e da distribuição de valores pelo vértice democratizante-socializante, o desejo do trabalho livre, e não pela mediação interessada e reprodutiva da ordem de exclusões reguladas pela forma de mercado, a mediação geral da acumulação em uma sociedade de 
classes. Deste ponto de vista, a perspectiva do trabalho na Cínica Aberta articula psicanálise e alguma virtualidade da vida pós-capitalista. É o nosso desejo. A clínica opera simultaneamente como cuidado e como política, como trabalho por transformação e trabalho da crítica. E os pacientes sabem disso, eles partilham esse desejo político desde o trabalho com o inconsciente com os analistas. Todos trabalham por si e para um além, indeterminado.

Podemos então observar a produção dos pacientes sobre essa oferta, e sobre si mesmos. Múltiplos tempos, compromissos e ritmos de análise; suspensão do caráter teleológico da experiência analítica; desmontagem de seus compromissos sociais territorializados; comunidade imaginada de pacientes que dividem o cuidado sobre a Clínica Aberta com os próprios analistas; gratidão expressa e gratidão política; transferência amorosa com o grupo de psicanalistas e com o espaço público que recebe o trabalho e efeitos subjetivantes, de caráter coletivo, plural e democratizante. Estes sentidos estão expressos nas pequenas frases recolhidas acima.

Além de proporcionar uma experiência do inconsciente, o que lhe é central, a Clínica Aberta é uma experiência de subjetivação, de efeitos políticos abertos, através da psicanálise que a sustenta em todos os seus pontos. O interesse dos pacientes por sua organização e o investimento dos analistas no próprio grupo de analistas revela um trabalho de fundo psíquico, de caráter dialético, em que o pensamento em relação e sobre a forma do outro - aqui uma forma social produzida, o analista grupal — fundamenta, através de estratos do movimento do próprio pensamento, uma identificação de fundo, fundamentalmente política. $O$ trabalho dos pacientes sobre o sentido daquela experiência, nova para eles, ainda inaugural em suas vidas e na vida social da cidade, leva também ao estabelecimento de si desde a experiência em relação a um outro, em um trabalho que se inscreve fortemente como um si mesmo. Os pacientes se sentem coautores da psicanálise que os recebe, e do dispositivo político que elegeram, por transferência em trabalho. De resto, essa é uma dimensão criadora de si da psicanálise, do método e do setting que - desde as observações originais sobre as necessidades de movimento psíquico de Berta Papenheim para seu médico analista Josef Breuer, que as ouviu, na experiência histórica número um da psicanálise — nunca deveria ter sido abandonada pela escuta e pela técnica psicanalítica (Ab’Sáber, 2016).

Outro ponto importante é a ideia de celebração e gratidão que atravessa todo o trabalho. É bem conhecido o momento de um narcisismo grupal que destaca o coletivo de modo erótico do restante da humanidade, que faz parte dos movimentos instaurados por uma psicanálise de grupos. Ou por grupos 
identitários, culturais, políticos e religiosos... No entanto, existe um excedente de erotismo nesse processo que podemos chamar de verdadeiro e estrutural: a existência de um objeto de civilização, uma análise pessoal, de modo livre dos mecanismos de controle e de acesso, de restrição e constrangimento, próprios das normas, barradas ao pensamento, da venda de serviços no mercado liberal de trabalho. Psicanálise livre da psicanálise organizada como mercadoria (Le Flore, 2016). Em termos clássicos de pensamento econômico psicanalítico, podemos dizer que a energia e o controle não gastos com o duro contrato liberal no mercado de serviços, que liga possibilidades psíquicas de modo predeterminado, em um ponto cego ideológico real do método, impensado, são forças que se tornam livres na modalidade pública de setting. Ao se dispensar o trabalho do contrato econômico liberal, seu desiquilíbrio ocultado e injustiça legitimada, libera-se espaço de experiência para o investimento no próprio trabalho analítico, e também para o transbordamento erótico e simbólico do encontro com um objeto bom, que por franqueado se torna criado pelo próprio paciente. Eticamente, falamos de um gesto de oferta amorosa e de interesse humano que efetivamente ultrapassa a razão da mercadoria, e a lógica subjacente ao encontro do mercado, que é campo de encontro, pesquisa e celebração, espaços políticos de geração de sentidos de outra ordem.

A clínica organizada para ser ofertada como nova economia da dádiva, por desejo político e erótico fundamental de seus trabalhadores, potencializa o aspecto transicional existente em toda psicanálise e em todo desenvolvimento humano: ela é um objeto sonhado de experiência, que está lá para ser vivido, na cidade tornada comum por um dia. Os pacientes encontram aquilo que, mais radicalmente do que outros settings sociais, sentem que também estão criando. Daí o erotismo, a alegria civilizatória, o efeito da gratidão, modalidade de vínculo amoroso, desconhecido em outros circuitos analíticos, que esse modo de dar ao mundo uma experiência do inconsciente freudiano produz.

Por fim, por enquanto, nos fica a indicação importante dos pacientes para a teoria do inconsciente e da relação de objeto transferencial em jogo, contraintuitiva: de que com o andamento do trabalho analítico na Clínica Aberta eles sentem uma reversão em seu sistema imaginário original, ligado à cultura e não à própria experiência, a respeito do que é a psicanálise e seu modo de fazer. Como dito por eles mesmos, podem passar a sentir que os encontros com os múltiplos analistas ao longo das sessões permitem mais movimento e mais liberdade do que aconteceria se estivessem sendo ouvidos por um único analista. $\mathrm{O}$ vínculo de tipo amoroso e a sustentação garantida de um trabalho qualificado com o inconsciente dissolve a ideologia "do psicanalista, seu divã 
e seu custo", reinaugurando o potencial primeiro de experiência aberta da clínica, tanto para paciente quanto para analista.

A resistência ao trabalho psíquico e os limites do potencial de criação fica referida, desta perspectiva, à forma do trabalho tradicional, invertendo a norma conhecida a partir da expansão do dispositivo. Bem ao contrário do que se supõe pelo senso comum psicanalítico e cultural. A psicanálise é uma experiência ético-teórica de transformação, que movimenta settings históricos imaginados para ela existir, e não algo fixada a uma forma de setting específico. De fato, nessa intuição de sua crítica à psicanálise, os pacientes parecem se referir aos múltiplos nós intermediários da multiplicação das cadeias associativas no espaço da formação do sonho. As cadeias latentes que, em sua multiplicidade — são sempre muito mais de uma — articulam o trabalho de conexão e desconexão de deslocamento e de condensação do psiquismo. Como disse um dia Didier Anzieu, o grupo é como o sonho.

Ao contrário da fantasia da integridade sólida do objeto individual como promotor de transferência, o analista único e intransferível clássico, a cadeia existencial de múltiplos analistas em escuta poderia funcionar como algo da multiplicidade dos nós psíquicos que organizam e reorganizam a rede de um sonho, desde o entendimento freudiano do que é um sonho, aumentando, em um princípio social e coletivo, a capacidade e a produtividade da mobilidade psíquica, essencial a qualquer natureza de transformação.

\section{Referências}

Ab'Sáber, T. (2016). Self cultural, sujeito do inconsciente e história. Livro eletrônico, São Paulo: e-galaxia.

Anzieu, D. (2004). Tornar-se psicanalista hoje. In Psicanalisar. Aparecida, SP: Ideias e Letras. (Trabalho originalmente publicado em 2000).

Bion, W. (1990). Notas sobre desejo e memória. In Melanie Klein hoje (vol. 2). Rio de Janeir, RJ: Imago, 1990. (Trabalho originalmente publicado em 1967).

Brown, W. (2016). El pueblo sin atributos. Barcelona, ESP: Malpaso.

Breuer, J., \& Freud, S. (2017). Estudos sobre a histeria. In Sigmund Freud, obras completas (Vol. 2). São Paulo, SP: Companhia das Letras. (Trabalho originalmente publicado em 1895).

Käes, R. (2006). A polifonia dos sonhos. Aparecida, SP: Ideias e Letras. (Trabalho originalmente publicado em 2002). 


\section{EDITORIAL}

Le Flore, R. (2016). The American gift economy. Livro eletrônico, Amazon.

Winnicott, D. (1988). Apetite e perturbação emocional. In Da pediatria à psicanálise. Rio de Janeiro, RJ: Francisco Alves. (Trabalho originalmente publicado em 1936).

Winnicott, D. (1988). A observação de bebês em uma situação estabelecida. Da pediatria à psicanálise. Rio de Janeiro, RJ: Francisco Alves. (Trabalho originalmente publicado em 1941).

Winnicott, D. (1984). Consultas terapêuticas em psiquiatria infantil. Rio de Janeiro, RJ: Imago. (Trabalho originalmente publicado em 1971).

Citação/Citation: Ab'Saber, T. (2021, dez.). Editorial. A clínica aberta e o analista-grupo: suas transferências e o comum. Revista Latinoamericana de Psicopatologia Fundamental, 24(4),501-511. http://dx.doi.org/10.1590/1415-4714.2021v24n4p501.1

Editoras/Editors: Profa. Dr. Nelson da Silva Jr. e Maria Livia Tourinho Moretto

Recebido/Received: 24.11.2021 / 11.24.2021 Aceito/Accepted: 25.11.2021/ 11.25.2021

Copyright: (C) 2009 Associação Universitária de Pesquisa em Psicopatologia Fundamental/ University Association for Research in Fundamental Psychopathology. Este é um artigo de livre acesso, que permite uso irrestrito, distribuição e reprodução em qualquer meio, desde que o autor e a fonte sejam citados / This is an open-access article, which permits unrestricted use, distribution, and reproduction in any medium, provided the original authors and sources are credited.

\section{TALEs Ab'SÁber}

Psicanalista; Membro do Departamento de Psicanálise do Instituto Sedes Sapientiae; Professor de Filosofia na Universidade Federal de São Paulo - Unifesp (São Paulo, SP, $\mathrm{Br})$. Autor, entre outros, de: $O$ sonhar restaurado, formas do sonhar em Bion, Winnicott e Freud (Editora 34, 2005); A música do tempo infinito (Cosac Naify, 2012) e Michel Temer e o fascismo comum (Hedra, 2018).

Rua Joquim Antunes, 490/21

05415-001 São Paulo, SP

luamartevenus@gmail.com

https://orcid.org/0000-0003-1761-6111

This is an open-access article, which permits unrestricted use, distribution,

\section{(cc) BY-NC} and reproduction in any medium for non-commercial purposes provided the original authors and sources are credited. 